\title{
Why play matters in a world of REF, TEF and What the Jeff
}

\author{
Alison James \\ University of Winchester
}

On April 28th 2017, I went on Twitter and found it bouncing with announcements, memes, gifs and pictures proclaiming \#edballsday. Now, I know who Ed Balls is - he's a dancer who was once a politician - but I have no idea how we came to have an Ed Balls Day; or, what one is. However, it really doesn't matter. It made me laugh and someone had written a brilliant poem dedicated to him and the point seemed to be the collective joke - something daft that brought people together to appreciate the enjoyment as much as the purported purpose. Virtually and dispersed, we were all momentarily playing together.

\#edballsday typifies a What the Jeff ${ }^{1}$ moment. It's a statement of incredulity that can be applied in so many contexts. What is this? What does it mean? How on earth did this come about? Questions that seem to apply whether we are ruminating on the Ed Balls phenomenon or our current ride on the ghost train of educational change. As I write, we are hurtling through the tunnel of pre-election legislative push-through, our white knuckles gripping the handle. Will we get thrown off on the next bend? Will we arrive safely at our destination? And if we do, what state will we be in? Elated by the thrill and clamouring for another go? Or queasy and doubtful we can take any more?

We all know what is lurking to go "BOO!" at us from different dark angles: Brexit, the Teaching Excellence Framework, Research Excellence Framework, changes to the quality landscape, student recruitment and general uncertainty. Three of these represent the intensification of the metric- and measurement-driven culture of Higher Education (HE). Singly, each can be daunting; clustered together, they are pretty terrifying. We are all dealing with them in multiple strategic and operational ways, some of which are obvious, whilst others - playing in response to difficulty - may seem counter-intuitive. However, playing in the face of challenge is something that we have done at Winchester recently and its success has surprised us.

This article is an informal account of our experimental 'Play and Creativity Festival': an event guided by some simple principles, the minimum of structure and few directives. Our mission was to (re)instate play at the heart of higher education community and activity, driven by four main desires. These were to

- celebrate and re-energise teaching and learning

- find alternative ways of communicating complex ideas and important messages

- generate fresh perspectives and new ideas

- build connections and community

The theoretical basis to our belief in play recognised that infinite forms of play exist - and they suit different people. We draw from Stuart Brown (2010), Pat Kane (2004), Brian Sutton Smith (2006), Robert Fagen (1981) and other eminent play theorists who argue that play is

\footnotetext{
${ }^{1}$ What the Jeff ?! Vernacular expression indicating surprise; polite equivalent of phrase using word starting with eff. Can be used in response to HE-related developments which are viewed as baffling or flawed.
} 
crucial to human learning, behavioural development and socialisation. Brown, in particular, defines play in its myriad forms as being pleasurable and apparently purposeless. And yet his research evidences that it is not just fun, but vital to our lives, as, when we play, we forge new neural pathways in our brains. These foster new ways of thinking and keep our minds alert. Not only this, but from compiling thousands of play case histories, he found that people who play demonstrate greater lightheartedness, empathy and optimism, particularly if they play physically. Through play, we build strength and agility, work out hierarchies and relationships, rehearse ideas and ways of being and chisel out new understandings. All of these are essential if humans are to remain responsive in the face of uncertainty and change.

With all of this in mind, it did not seem too much to suggest that the university sector needs play and players now more than ever. And so the idea of a 'Play and Creativity Festival' was born and the real thing ran from April $3^{\text {rd }}-7^{\text {th }} 2017$. It came from a leadership development programme generating projects to enrich the life of the University. Play and creativity were already at the heart of my interests through my work on creative reflection and PDP, as a LEGO® SERIOUS PLAY® facilitator and through collaborations with Chrissi Nerantzi and Prof. Norman Jackson on Exploring Play in Higher Education (Creative Academic CAM2a and 2b, 2015). Before joining the University in September 2016, I felt sure that the community would be playful and creative in ways it did not necessarily make visible. To my joy, I found like-minded partners in Julia Osgerby, Tina Newman and Sheila Nicholson and the four of us bid for senior sponsorship to back us in designing and running the Festival. We honestly didn't know if this would be forthcoming: would the idea sound inappropriate at a time of nervy horizon-scanning, the need to funnel resources strategically, the overwhelming demands on staff and students at the end of the semester? To our delight, however, we won complete support... and we were off!

Our starting point was our belief that playful and creative engagement was essential for reenergising, bolstering morale, lightening the load, refreshing ideas and strengthening community. However, we had no fixed blueprint for action. Even though we were excited by the prospect, we also had no idea if anyone would want to join in; so, we decided to hold an open meeting, inviting people to come and explore with us what shape the Festival might take and how to put it on. As part of this, we invited our colleague and soon-to-be fellow musketeer Richard Cheetham, from Sports Coaching, to run an eight-minute exercise with balloons to loosen us all up.

Two things blew us away. One was that forty people turned up for this meeting. The other was that, in eight minutes, while forty 'almost strangers' ran around the room following instructions as to what to do with our balloons, we learned several things: lots about heart rate, mobility, coordination, team working, but even more about how much we laughed and how differently we felt at the end of that brief runaround. It energised our thinking and helped us frame what to do next. One of the most important outcomes was the over-riding view, voiced by those in the room, that this was not just something we could or should do - we needed to do it. It was clear that if balloon play could bring home to participants complex concepts relevant to body functioning and sports science, there must be countless other playful ways to inspire learning. 
Whilst the pedagogic side of the Festival was of paramount importance, we agreed we wanted to give staff in any role - and students - the chance to contribute and/or to participate. We adopted an open and organic philosophy, which welcomed anyone from anywhere to do so something in Festival week - they chose the activity and organised it; we promoted it widely through a programme. We did not envisage a nice, neat, systematic conference, but something widespread and unexpected - a bit like lovely mushrooms popping up in unusual places. And so the organised, serendipitous not-quite-chaos began. The core team rapidly expanded with more play aficionados - Amy Barlow, Cassie Shaw, Jack Hancock, and Bekki Street - who threw more ideas into the mix and helped us gather momentum and offers of activities.

Through the Festival, we were both shaping and feeding from a shift, palpable over the last three years, in the zeitgeist of HE. Play is starting to be recognised as a valid part of university life in all its forms and aspects. One strand of play, gamification, has become a popular topic in journal articles which recount how the principles, rules and characters of game-playing are being adopted for high-level teaching. Building on our earlier ventures together, Chrissi Nerantzi and I are producing an international collection of play practices in HE for Palgrave Macmillan (2018). Play has suddenly become a hot conference topic, as in the National Teaching Fellow Symposium (2016) and at the PlayLearn conferences at Manchester Metropolitan University (2016/2017).

However, there is still work to do to ensure that play in HE is as roundly appreciated as things like 'innovation' and 'creativity', buzzwords which seem universally popular, whilst 'play' is a word that attracts some but makes others feel uneasy. This is often because the true nature, scope and relevance of play has been misinterpreted as something that children do and grow out of, confined to the social and leisure-based. At worst, it is considered trivial or something we do instead of the real and important. The pedagogic challenge of integrating play into HE teaching is to intrigue, inspire, stretch and amuse students by unexpected approaches to a subject, whilst not pitching the play in ways that feel childish or discomfiting.

With this balance in mind, by the time the first day of the Festival had arrived, I was wondering what we had let ourselves in for. However, I was also overwhelmed by the buzz that had built up; with well over sixty sessions running, we were turning away offers right up to the moment it started. Participants and contributors ranged from the Vice Chancellor, Assistant and Deputy Vice Chancellors to academics, students, administrators, professional services staff and more. We even had messages from colleagues in a Korean university, saying that, if they had only known about it, they would have flown over. We went from being nervous about whether people would take part to slack-jawed at the ways they responded.

The kinds of play that populated the Festival were incredibly diverse, from events which had purposeful outcomes to those which were open and free. Some were solitary or quietly communal (jigsaw building, no-sew bunting making, sensory drawing with blindfolds and music); others invited louder, more active participation, such as scientific demonstrations conducted through maggot 'racing' (to understand aspects of forensics) or playing catch in the dark to illustrate aspects of cycling safety and the design of appropriate bike lights. There was physical rough-and-tumble in the shape of a re-run of the balloon activity, this time with over thirty coaching students. Somehow, I ended up playing sitting volleyball with some 
third-year drama students, heady after the relief of their final hand-in. (To my astonishment, this was a hoot, although I ruined my beige trousers sliding across the sports hall.) The physical and participatory examples listed here all came from current curriculum practice and further revealed that playful pedagogies are being used to good effect on our programmes.

Some challenges were literally puzzling - learning to break code like Sherlock Holmes, or trying to grasp the niceties of eighteenth-century hand gestures and protocols for dramatic performance. There were gentler outdoor enquiries too: the Secret Life of Campus Tour combined history, geography, biodiversity, environmental sustainability and a nice healthy walk, all in one package. There were music, performance, making, sticking, LEGO building, voice and body workshops, a lecture, ceramic painting, digital gaming, labyrinth walking and imaginative contemplation. And soooooo many others! All provided the opportunity to come together and learn about a subject - and often inspired ideas about how to teach in new and unexpected ways. We rounded off Festival week with a 'Clarice Cliff tea party'; one of the most popular drop-in events of the week had been the chance to paint slipware in the style of Clarice Cliff - with artworks, guidance materials, music of her time and a wonderful array of found, donated and gathered plain china for colleagues to decorate. These were all dried by the Friday and the table set for cake and tea amidst a riot of ceramic shapes and vivid colours.

If you have read this far, I hope some of the excitement of the Festival and the beliefs which inspired it are coming across to you. Even if you think it sounds fun, you might still be wondering what the point of it was and whether it will have lasting impact. You may also be asking what its relevance was for teaching and learning. I shall try to pull together some thoughts to conclude.

We were keen to capture, in a non-invasive way, responses to the events of the Festival and thoughts as to its value, by means of interviews and paper evaluations. Some of the former can be found in our memento film of the Festival on our blog homepage here:

https://playandcreativityfestival.wordpress.com/. Extensive written feedback supported our hunch that although we are often playful and creative we do not always make this visible. It confirmed that by sharing these practices we enjoyed noticeable benefits. From a pedagogic point of view, these included learning new skills and techniques and combining unusual subjects, materials and approaches to embed concepts or stimulate thinking. Participants repeatedly remarked on the value of integrating play into teaching complex subjects. Teaching staff were inspired to modify approaches for application to their own contexts, whilst students emphasised how stimulated by activities they felt. A playful, round-campus nature walk, designed to raise awareness of sustainability and biodiversity, triggered ideas about how to use such an approach to develop language teaching. An activity with peas and sticks was seen as an effective way of communicating the history of Froebel to Education students. Three illustrations of transferability as well as value for teaching can be seen here:

- "I feel very privileged to have seen this - This was a fascinating mix of Art, theatre, Exhibition, Play and Poetry reading as well as being a scientific treatise on the physics and chemistry of clouds (The Naming of Clouds; a performance)"

- "This was an excellent opportunity to engage physiologically, emotionally and socially to use our voices. We used our bodies and our voices to make sound in a way that was conscious, purposeful and self- aware ...(Playing with Voice: workshop)" 
- "Who constructs, controls curates? Really interesting questions for each of us... relevant to all programmes - this exhibition would be a great resource across all faculties (The pop-up Winchester American Museum, exploring questions of content and ownership)"

A recent graduate of the University, working in student engagement, noted the true partnership value of experimenting together:

"There was no hierarchy in the sessions, no student-teacher dichotomy, everyone was equally new to the activity and they learnt together. The week was a refreshing and reinvigorating opportunity for staff and students to put down their pens, stop typing, and equally engage in play."

Julia, a core team member, reflecting on the Festival, afterwards wrote:

"I lecture in Accounting and I am always trying to find new and interesting ways to keep students engaged with what can be perceived to be a dull and boring subject. I was initially drawn to getting involved in the Festival as I knew very little about play and creativity in the higher education context. The Festival allowed me to discover the pedagogy behind play and creativity. It provided me with a wonderful opportunity to explore how I could use play and creativity in my teaching practice. It also created a productive and exciting forum to share and discuss best practice with colleagues from my own Department and other colleagues from different disciplines and backgrounds from across the University."

In an HE culture driven by targets, benchmarks and metrics, participants repeatedly noted what they could do when the pressure was off and the opportunity to explore was openended. Sessions were an antidote to wistful laments by academics about the loss of learning for learning's sake or the pleasure of playing without agenda.

There were other positives too.

We fulfilled our ambition to lift spirits and re-energise people in the final crazy taught week of Semester 2. There is never a good time to run any kind of major event and this particular week did at times feel like a bonkers choice. However, we felt that, actually, when you are overstretched and stressed and exhausted and the Easter holiday is just NEVER coming that is in fact when you need to take time out and do something else. This could be for fifteen minutes, or for an hour, or longer. Student participants agreed.

The Festival certainly consolidated our sense of community and connection - time and again people fed back that they were having conversations they would not usually have, with people they would not usually talk to. We all played with people we never come across as a rule and people took part who six weeks earlier had really looked as if they wouldn't. A colleague who, if not sceptical, certainly was not sure that it was for her, observed afterwards that "the Play and Creativity Festival was marvellous, and it really brought people together".

Others remarked that a really important - but unintended - benefit of the Festival was that it served as a form of professional development, but not of the conventional kind. Sessions 
gave people new perspectives and ideas for tasks, approaches, teaching, relationships, team building, all of which were transferable in some way to entirely different fields.

Let me also touch upon the no-small-matter of staff wellbeing. The atmosphere in the sessions that I participated in - and trust me, I went to loads; I felt I had to! $(-)$ - was unfailingly collegiate, interested and good- humoured and the activities themselves were all eye-opening. With all the regularity of a refrain, people said that they felt calmer and happier as a result of participating. A final plus is that the Festival was relatively economical to put on - we organised and ran it ourselves and, whilst we did draw on small amounts of budget to pay for resources and some basic promotional materials, it cost a fraction of a major conference. Though it was a huge undertaking, somehow it bowled along and did not feel like work. Above all, it was fun.

Was it perfect? Of course not. The wind blew our lovely banners down. Our festival T-shirts turned up battleship grey instead of navy blue and the small ones wouldn't have fitted a mole. We said from the outset that it was an experiment, that it would be homespun, that we couldn't guarantee who would attend sessions as it was all organised on a pot-luck basis. The potluckery was both part of the charm and freedom and also something to reflect on; some sessions were extremely well-attended and others much quieter. This was no reflection on the quality of the contribution, but down to such variables as timing, location and local promotion. I invited a colleague from outside the University to run an outdoor workshop, as long as she didn't mind not knowing who might be there. I joked to her that if no-one turned up it might just be her and the West Downs cat. Shortly after her session started, she sent me a photo. Of the cat. Thankfully, others joined them moments later.

We travelled a long way in the three months leading up to the Festival and saw an awakening within the community as to what it could do for us. It is now August 2017 and since I first drafted this there have been numerous enquiries from colleagues in other universities as to how they might run a similar festival. We have been happy to discuss our experiences widely, but the true key to the success of this kind of venture is simple: it is both believing in the value of doing it and also giving yourselves as a community permission to play. We had, most helpfully, senior-team backing, but local, individual will is important, too; through our enthusiasm and belief, we got the buy-in of a wide constituency. We presented the film at the Governors' Awayday and received their blessing to run annual festivals. We are now planning the next one and looking at how we can involve our local community. In our midst, we now have a growing number of play evangelicals, all fired up to develop the event. The Festival even won a Senate Learning \& Teaching Award and received the the following statement of support from the First Deputy Vice Chancellor:

"The festival was a perfect example of research-informed pedagogy. Built upon the research into play as a form of learning, the festival provided a forum for imaginative, challenging and fun pedagogic practice which, in turn, inspired colleagues to review their own pedagogic practice and open themselves to the possibility of incorporating elements of play. We hope the festival will continue and build upon this excellent start and become a distinctive part of Winchester's learning and teaching practice."

Bring on Play and Creativity 18 ! 


\section{Reference list}

Brown, S. (2010) Play. How it Shapes the Brain, Opens the Imagination and Invigorates the Soul. New York: Penguin.

Fagen, R . (1981) Animal Play Behaviour. Oxford: Oxford University Press.

Kane, P. (2004) The Play Ethic. A Manifesto for a Different Way of Living. New York. Macmillan.

Nerantzi, C. and James, A. (2015) 'Waterfall of questions or can we afford not to play in HE?' In: Nerantzi, C. and James, A. (eds.) Exploring Play in Higher Education. Creative Academic Magazine, 2A, June 2015, 4-5. Available at: http://www.creativeacademic.uk/ (Accessed: 18 September 2017.)

Sutton Smith, B. (2006) 'Play and Ambiguity.' In: Salen, K. and Zimerman, E. (eds.) The Game Design Reader. MIT Press. Available at:

http://creativegames.org.uk/modules/Intro Game Studies/Sutton-

Smith Play\%20and\%20Ambiguity Excerpt-1997.pdf (Accessed: 18 September 2017.) 